\title{
The Process of Teaching Psychology Students to Connect with One's Own Sensible Reality: The Efficaciousness of Haiku Poems
}

\author{
Rosangela Bertelli \\ Universidade de Trás-os-Montes e Alto Douro, \\ Escola de Ciências Humanas e Sociais, \\ Quinta de Prados, 5001-801, Vila Real, Portugal
}

\begin{abstract}
The cognitive-behavioural model of learning is grounded on the idea that our thoughts influence our behaviours through a process of conditioning and it anticipates that whenever we can change our thoughts, our behaviours will change. This model of learning is at the foundation of the cognitive-behavioural interventions employed to treat mental health symptoms and mental health disorders. The mere abstract knowledge, separated from embodiment, about the cognitive-behavioural model of learning does not however offer to psychology students the required understanding of this conditioning process. The students need somehow to connect with one's own sensible inner reality during the educational process. It was hypothesised that expressive arts activities, with their own alternative languages, would endow the psychology students making it easier for them to access their automatic thoughts (movements of memory). In order to test this, a procedure prompted by the SADUPA poetry technique was carried out. A qualitative analysis of the results obtained revealed changes in language associated to the Haiku expressive art activity, a growing psychological presence, awareness of one's automatic cognitive flows, and a manifested receptivity to a more experiential based teaching.
\end{abstract}

Keywords: Cognitive-Behavioural Model of Learning, Expressive Arts, Haiku Verse Form, Poetry, Streaming of Automatic Thoughts, Teaching Psychology Students

\section{INTRODUCTION}

The cognitive-behavioural model of learning is grounded on the idea that our thoughts influence our behaviours through a process of conditioning and it anticipates that whenever we can change our thoughts, our behaviours will change. The model further estimates that these modifications will result in changes in our opinions, judgments, in our views and interpretations of events, and also in changes in our notions about the Self, the Other and the world around us [1].

\section{Cognitive-Behavioural Interventions}

The cognitive-behavioural model of learning is at the foundation of the cognitive-behavioural interventions employed to treat mental health symptoms and mental health disorders. It conceives of that we all carry simple notions and profound notions, which were sculpted through the experiences we knew during our childhoods, and that the deeper types of notions, those which create mental health problems and disturbances, are usually negative notions. When we find ourselves in certain situations that cause tension (selective pressures), automatic thoughts arise, which are thoughts that flow regardless of our will.

Those thoughts that spring from our deepest (core) negative notions are usually negative thoughts, which spark dysfunctional reactions. These reactions imply physiological changes in mood, which influence, on the one hand, our actions and, on the other hand, those reactions 
may even activate additional, surplus, automatic thoughts. Because we have within us distorted notions about ourselves, others and the world, such notions condition our styles of thoughts and that is when unhealthy, insalubrious ways of thinking, conceiving, imagining or recalling settle on. Cognitive distortions are consistent mistakes in the logic of our automatic thoughts, which result from the deepest negative notions (core) rooted in our cognitive structure. When our deepest notions (core) blend in with events that produce strain, streams of negative automatic thoughts are activated, and these same thoughts guide our behaviours [1].

\section{Teaching Psychology}

Learning activities that impart knowledge or skill and that call to a state of preparedness or ability to identify automatic thoughts without difficulty, in the absence of selective pressures, are crucial in the process of teaching psychology students and thus in the process of personal and professional development of cognitive-behavioural clinical psychologists [2, 3].

The mere abstract knowledge, separated from embodiment, about the cognitive-behavioural model of learning does not offer to psychology students the required "Overview Effect" for a felt and deep understanding of the interconnectedness of the factors involved in this cognitivebehavioural conditioning process $[4,5]$. In other words, subjective qualities associated to the "Overview Effect", for instance, being able to watch our own pouring of thoughts, our awe when keeping an eye on our currents of thoughts, and recognising our own deep-seated notions, must all be sensed in order for us to become elucidated about the reasonability of that idea that our automatic thoughts influence our symptoms that influence our behaviours.

Rather than just teaching theoretically the cognitive-behavioural model of learning and its psychotherapeutic procedures to psychology students, teaching psychology could also furnish to psychology students some existentially based teaching or, in other words, some experiential based teaching. Theoretic teaching followed by existential teaching might allow for the psychology students to get in touch or to connect with one's own sensible or felt inner reality, thus conducting to one's appreciation of that which exists internally, one's own manifested automatic cognitions. The plain consequence of such a routine would thereby be the possibility of one's detecting, noticing, observing within oneself the very cognitive-behavioural theoretical model of learning previously studied only in the abstract $[2,3]$.

\section{Expressive Arts}

Expressive arts activities, such as poesy, drawing, colouring in, dance, drama represent patterns of alternative languages, non-discursive, non-linguistic communication and expression, which potentially facilitate our access to our automatic thoughts (movements of memory), our willingness to acknowledge the contents of our automatic cognitive flows, and thus allow us to overcome the disadvantages inherent to our difficulties in the transmission of our own feelings, beliefs, impressions, notions [2, 6].

In order to supply to the psychology students an artistic means of expression with the aim of facilitating their discovery within themselves of the very cognitive-behavioural constructs that they previously studied and learnt only abstractly and theoretically, a procedure inspired or prompted by the SADUPA poetry technique was carried out [7]. SADUPA is a Haiku verse form procedure where Haiku (a neologism), a kind of classical Japanese poetry, an epigrammatic verse pattern born in Japan at the end of the XIX century, consisting of three short lines and very simple language, represents an expressive art activity $[7,8,9]$. 


\section{METHOD}

\section{Participants}

Six psychology students participated in at least six of the seven sessions of training of personal and professional development of cognitive-behavioural clinical psychologists and produced individual written records for each of the sessions. Those records held the students' comprehended mental experiences for each of the sessions, the contents of their direct inner observations.

\section{Materials and Procedure}

The process of teaching psychology students demanded four phases. The first phase of the teaching process involved the theoretical study of the basic model of cognitive-behavioural learning. The second phase of the teaching process focused on the theoretical study of the procedures used in order to identify automatic thoughts. The third phase of the teaching process involved the theoretical study of procedures used with the objective of modifying dysfunctional cognitions. In the fourth phase of the teaching process, the training of personal and professional development began, that is, in this last phase students had the opportunity to get in touch with their own sensitive and felt reality and to capture what exists, the manifest. For this existential phase, which covered seven sessions, a procedure of expressive art activity using Haiku, classical Japanese poetry, was carried out.

For each of the first six sessions of the fourth phase (the existential phase) of the teaching process, psychology students listened to the reading of two Haikus per session. The total of 12 Haikus read to the psychology students during those six sessions were written by Matsuo Bashô and were extracted from Bashô's "O eremita viajante" [8]. For the seventh session of this fourth phase (the existential phase), however, psychology students were asked to compose their own free Haiku which should synthesise their comprehended mental experiences during the training of personal and professional development.

The first six sessions complied with the following practice: a) The procedure for the training session was presented; b) A sheet of drawing paper cut into a rectangular shape $(29.5 \mathrm{~cm}$ long by $10.5 \mathrm{~cm}$ wide) was given to each student and the students could then decide in which direction to use it; c) A Haiku was read aloud, paused between each of the three lines; d) There was a five-second silence; e) The Haiku was read aloud again, excluding its second line; f) The students then wrote, on the rectangular sheet, a line to fill in the excluded one in the second reading, giving the poem a personal meaning; g) After writing the second line, a second Haiku was read aloud, paused between each of the three lines; h) There was a five-second silence; i) the second Haiku was read aloud again, excluding its second line; j) The students then wrote, on the rectangular sheet, a line to fill in the blank left between the first and third lines, giving to the second poem a personal meaning; $\mathrm{k}$ ) When the students finished writing the second line, the sheets containing the two lines composed by each student were collected; l) A new sheet of drawing paper cut into a rectangular shape ( $29.5 \mathrm{~cm}$ long by $10.5 \mathrm{~cm}$ wide) was then delivered to each student and the students decided in which direction to use it; $m$ ) The students then prepared their written record of their comprehended mental experience for that training session; n) Records were collected.

The seventh session followed a different dynamics: a) A sheet of drawing paper cut into a rectangular shape ( $29.5 \mathrm{~cm}$ long by $10.5 \mathrm{~cm}$ wide) was given to each student and the students decided in which direction to use it; b) Students were asked to, freely, without any restraint, compose a full (three short lines) Haiku synthesising their own comprehended, fully understood or grasped, perceived mental experiences during the training of personal and professional development; c) After the composition was completed, the sheets of drawing 
paper were collected; d) A new sheet of drawing paper cut into a rectangular shape $(29.5 \mathrm{~cm}$ long by $10.5 \mathrm{~cm}$ wide) was delivered to each student, who decided in which direction to use it; e) The students then prepared their written record of their comprehended mental experience for that last training session; f) Records were collected.

Having all those written records, a single set of records, chosen at random, produced by only one of the six psychology students, was subjected to discourse analysis. Written records about the first and the seventh sessions were analysed for their discursive categories, with the aim to identify changes in language and illustrate the student's narrative on her mental experiences grown out of the Haiku expressive art activity [10,11,12]. Variations in discourse were described by categorizing the terms she used (pronouns, verbs, and nouns) as they happened in the first and the last sessions' written records. Changes in language might reflect for instance the student's changes in engagement during the existential phase of the teaching process [13, 14].

In describing our unique experiences with the existential phase, the subjective nature of our comprehended mental experiences provides valuable information about our thoughts, beliefs, behaviours, and about the efficacy of the Haiku poem procedure as a potential expressive art activity for the teaching of psychologists.

\section{RESULTS}

In order to examine the student's own connect with her own sensible reality, the student's first and last written records were analysed for their discursive categories. Pronouns, Verbs and Nouns used and their respective number of occurrences were identified. Pronoun is a word that represents or replaces a name and a personal pronoun is a word which designates the people in the speech. Verb is a grammatical class of words that designate action, process or state, and Noun is a word that names a being, thing, action, state, quality.

\section{First written record}

In her first written record of her comprehended mental experiences, the personal pronouns I (4 occurrences) and They (1 occurrence) were identified. For the verbs, Chirping (1 occurrence), Contemplating (1 occurrence), Cultivating (1 occurrence), Feeling (2 occurrences), Seeing in one's mind (2 occurrences), Staying / Spending time (4 occurrences), Summing up (1 occurrence), and Working (1 occurrence) were chosen by the student. The following nouns Air (1 occurrence), Birds (1 occurrence), Calm (1 occurrence), Childhood (1 occurrence), Clarity (1 occurrence), Experience (1 occurrence), Freshness (1 occurrence), Land (1 occurrence), Melancholy (1 occurrence), Nature (2 occurrences), Reading (1 occurrence), Remembrance (1 occurrence), and Time (1 occurrence) were discovered.

\section{Seventh written record}

In her last written record the personal pronouns I/me (6 occurrences), We/Our (2 occurrences), and They (1 occurrence) were identified. The verbs Accumulated (1 occurrence), Addressed (1 occurrence), Allowing (1 occurrence), Be (8 occurrences), Bring (2 occurrences), Empty (1 occurrence), Give (2 occurrences), Leave (1 occurrence), Make (1 occurrence), Represent (1 occurrence) Seeing in one's mind (6 occurrences) were placed. The nouns Animals (1 occurrence), Attention (2 occurrences), Bunch (1 occurrence), Cherry (1 occurrence), Childhood (2 occurrences), Colour (1 occurrence), Days (3 occurrences), Elements (1 occurrence), Emphasis (1 occurrence), Factor (1 occurrence), Freedom (1 occurrence), Fruits (1 occurrence), Joy (1 occurrence), Last (3 occurrences), Melancholy (2 occurrences), Mind (1 occurrence), Nature (1 occurrence), Novelty (1 occurrence), Objective (1 occurrence), Poem (1 occurrence), Problem (1 occurrence), Scenery (1 occurrence), Session (8 
occurrences), Space (1 occurrence), Sun (1 occurrence), Surrounding (1 occurrence), Task (2 occurrences), Tension ( 1 occurrence) Thing ( 1 occurrence), Time (1 occurrence), and Wings (1 occurrence) were appointed.

\section{Connecting with one's own sensible reality}

The narrative in her first written record tells the particulars about her brain's reaction to the existential phase of teaching. She noticed the automatic movement of her memory, and watched the discharge of thoughts: "...I saw in my mind childhood memories..."; "...I felt melancholy..."; "...I saw in my mind the birds chirping, the freshness and clarity of the air..."; "...spent the afternoons in the midst of Nature..."; "...adults worked and cultivated the land..."; "...it was a pleasant mental experience..."

The narrative in her seventh (last) written record keeps on telling the particulars about her mental experiences during this Haiku verse form phase: “...The poems addressed elements of Nature..."; "...Winged animals represent freedom to me..."; "...The sessions brought me tranquillity, joy, and melancholy..."; "...I saw in my mind childhood times..."; "...The sessions reminded me of the little things that are around us every day and that we fail to pay attention to..."

Her free Haiku composition synthesising her fully understood mental experiences during the existential phase of teaching or, in others words, the training of personal and professional development, also tells the particulars about her mental discoveries about herself, about the basic model of cognitive-behavioural learning, and about automatic pouring of thoughts, standing as proof of her inner experiences (or her connect with her own sensible reality) stemming from this activity of expressive art:

The first rays of light emerge

Focusing on a ripe bunch of grapes

That feeds a young blackbird

\section{DISCUSSION}

The clinical psychologist who adopts cognitive-behavioural psychotherapeutic strategies in the treatment of symptoms of mental health disorders must represent or express something abstract in tangible form, or, in others words, must incarnate the meaning and the reality of the awareness of one's own automatic thoughts. It is not enough to bring to the task just the academic abstract knowledge of the existence of some cognitive flows that govern our emotions and our actions. This means that the training of cognitive-behavioural clinical psychologists must not neglect the necessity of awakening of the students to one's own inner reality. In the case of the cognitive-behavioural interventions such inner reality makes reference to one's access and knowledge of one's own cognitions and associated emotional reactions and behaviours. Embodying awareness facilitates not only understanding and entering into another's feelings, but perhaps first and foremost it facilitates making plain and comprehensible to the patient the abstract central principles and main elements of the cognitive-behavioural psychotherapies.

The context in which the students were experiencing a Haiku verse form was central: The context was the training of personal and professional development of cognitive-behavioural clinical psychologists. In that sense any change in language from the first to the seventh written register was significant, because such changes would potentially provide evidence for the students' access to automatic cognitions and emotional reactions. For instance, a pronoun is a word that represents or replaces a name. Personal pronouns are important, because they are naturally prompted by a person's psychological presence in his/her narrative. 
In her first written record the student pronounced "...I saw in my mind childhood memories..."; "...I felt melancholy...", and "...I saw in my mind the birds chirping, the freshness and clarity of the air..." The pronoun I was clearly stated. That might mean that she (the student) was psychologically present. On the other hand, she said "...spent the afternoons in the midst of Nature..." Who did? Who spent the afternoons there? There is no pronoun. The unavailability of a pronoun might mean the use of a distancing language, which might mean the psychological distancing from the content of that movement of memory (stream of automatic thoughts). Another example, “...adults worked and cultivated the land..." Who did? Who were the adults? Were they her parents or perhaps some family relationships? Again she uses a distancing language, which might mean psychologically distancing herself from that memory, from those adults. Was there an inadequate relationship between her and those adults? The expressive art activity (Haiku verse form) seems to have touched off currents of thoughts. She finishes her first written record saying "...it was a pleasant mental experience..." This is passive voice which might indicate again psychological distancing from the discourse or from the events crossing her mind at that particular moment.

In the seventh written record the student pronounced “...The poems addressed elements of Nature..." This was unnecessary information, thus it must be somehow important to her and perhaps it might be associated to her previous recollections of "...afternoons in the midst of Nature..." and "...adults working and cultivating the land..." She also articulated "...Winged animals represent freedom to me...", “...The sessions brought me tranquillity, joy, and melancholy...", "...I saw in my mind childhood times...", “...The sessions reminded me of the little things that are around us every day and that we fail to pay attention to..." It is noticeable here the change from the first written record in the sense that in this last record the personal pronouns "I" and "me" are clearly conveyed in words which might show that the student was undoubtedly psychologically present when writing down her mental experiences during the last session. The use of "us" and "We" might imply cooperation and it might be considered evidence of awareness of the cognitive flows experienced with the Haiku sessions, it might indicate more willingness or readiness to receive a more existentially based teaching or it might manifest receptivity to the training of personal and professional development of cognitive-behavioural clinical psychologists.

\section{CONCLUSION}

The process of teaching just described to connect psychology students with one's own sensible reality and the results obtained provided the necessary grounds to support the efficaciousness of a Haiku verse pattern procedure for the personal and professional development of cognitivebehavioural clinical psychologists.

In order for the patient to discover the interpretations that lead him or her to feel and to act in a certain way, it is mandatory that the patient himself or herself learn to look inside oneself and see and accept it without judgment the information transmitted by his or her own current of thoughts. In order for the psychologist to teach the patient how to proceed, it is necessary that the psychologist knows his or her own thoughts, feelings and behaviours.

The process of teaching psychology students to connect with one's own sensible reality is vitally necessary, of the greatest importance, and should be furnished without wounding and preferentially by supplying enjoyment during the learning process. 


\section{References}

Beck, J. S. (2011). Cognitive behavior therapy: Basics and beyond (2nd ed.). New York: Guilford Press. ISBN 978-160918-504-6

Bertelli, R. (2019a). The application of an expressive arts activity for the very first session of training of personal and professional development of cognitive-behavioural clinical psychologists: Cognitive content as proxy data to study core beliefs. Advances in Social Sciences Research Journal, 6(7), 599-605. doi:10.14738/assrj.67.6841

Bertelli, R. (2019b). Schooling cognitive-behavioural clinical psychologists: Expressive arts activities as potentially favourable conditions which facilitate one's observing of one's own streaming of automatic thoughts. Journal of Arts \& Humanities, 8(10), 1-6. doi: http://dx.doi.org/10.18533/journal.v8i10.1740

Yaden, D. B., Iwry, J., Slack, K. J., Eichstaedt, J. C., Zhao, Y., Vaillant, G. E., \& Newberg, A. B. (2016). The overview effect: Awe and self-transcendent experience in space flight. Psychology of Consciousness: Theory, Research, and Practice, 3(1), 1-11. doi: 10.1037/cns0000086

Haqq-Misra, J., Som, S., Mullan, B., Loureiro, R., Schwieterman, E., Seyler, L.,... Sullivan, W. (2017). The astrobiology of the Anthropocene. A white paper for the National Academy of Sciences.

Harris, D. A. (2009). The paradox of expressing speechless terror: Ritual liminality in the creative arts therapies' treatment of posttraumatic distress. The Arts in Psychotherapy, 36, 94-104.

Santarpia, A., Dudoit, E., \& Paul, M. (2015). The discursive effects of the Haiku-based SADUPA poetry technique in palliative care. Journal of Poetry Therapy, 28(3), 174-194. https://hal-amu.archives-ouvertes.fr/hal-01180712. HAL Id: hal-01180712

Bashô, M. (2016). O eremita viajante. Haikus: Obra completa. Porto: Assírio \& Alvim. ISBN: 978-972-37-1920-8

National Geographic Portugal. (Fevereiro, 2008). No rasto de um fantasma. National Geographic SOC, 60-73.

Auerbach, C. F. \& Silverstein, L. B. (2003). Qualitative data: An introduction to coding and analysis. New York: New York University Press.

Bardin, L. (1977). L'Analyse de Contenu. Paris: Presses Universitaires de France.

Blanchet, A. (1991). Dire et faire dire: L'entretien. Paris: A. Colin.

Sijercic, I., Button, M. L., Westra, H. A., \& Hara, K. M. (2016). The interpersonal context of client motivational language in cognitive-behavioral therapy. Psychotherapy, 53, 13-21. https ://doi.org/10.1037/pst00 00017.

Lombardi, D. R., Button, M. L., \& Westra, H. A. (2014). Measuring motivation: Change talk and counter change talk in cognitive behavioral therapy for generalized anxiety. Cognitive Behaviour Therapy, 43, 12-21.

https://doi.org/10.1080/16506073.2013.84640 0. 